\title{
Ocean-Atmosphere Coupling in the Monsoon Intraseasonal Oscillation: A Simple Model Study
}

\author{
Gilles BeLlON \\ Department of Applied Physics and Applied Mathematics, Columbia University, New York, New York
}

AdAm H. Sobel

Department of Applied Physics and Applied Mathematics, and Department of Earth and Environmental Science, Columbia University, New York, New York

JEROME VIALARD

Institut de Recherche pour le Développement, Laboratoire d'Océanographie-Expérimentation et Approches Numériques, Institut Pierre-Simon Laplace, Université Pierre et Marie Curie, Paris, France

(Manuscript received 30 October 2007, in final form 14 March 2008)

\begin{abstract}
A simple coupled model is used in a zonally symmetric aquaplanet configuration to investigate the effect of ocean-atmosphere coupling on the Asian monsoon intraseasonal oscillation. The model consists of a linear atmospheric model of intermediate complexity based on quasi-equilibrium theory coupled to a simple, linear model of the upper ocean. This model has one unstable eigenmode with a period in the 30-60-day range and a structure similar to the observed northward-propagating intraseasonal oscillation in the Bay of Bengal/west Pacific sector.

The ocean-atmosphere coupling is shown to have little impact on either the growth rate or latitudinal structure of the atmospheric oscillation, but it reduces the oscillation's period by a quarter. At latitudes corresponding to the north of the Indian Ocean, the sea surface temperature (SST) anomalies lead the precipitation anomalies by a quarter of a period, similarly to what has been observed in the Bay of Bengal. The mixed layer depth is in phase opposition to the SST: a monsoon break corresponds to both a warming and a shoaling of the mixed layer. This behavior results from the similarity between the patterns of the predominant processes: wind-induced surface heat flux and wind stirring.

The instability of the seasonal monsoon flow is sensitive to the seasonal mixed layer depth: the oscillation is damped when the oceanic mixed layer is thin (about $10 \mathrm{~m}$ deep or thinner), as in previous experiments with several models aimed at addressing the boreal winter Madden-Julian oscillation. This suggests that the weak thermal inertia of land might explain the minima of intraseasonal variance observed over the Asian continent.
\end{abstract}

\section{Introduction}

Intraseasonal variability is a salient feature of the Asian monsoon. This variability times and modulates the dry spells (the "breaks") and rainy periods ("active phases") over the continent during the monsoon season. These in turn regulate the abundance of crops and

Corresponding author address: Gilles Bellon, Columbia University, Lamont Campus, 61 Route 9W, Monell Building, Palisades, NY 10964-8000.

E-mail: gilles@iri.columbia.edu the occurrence of extreme events (floods and droughts). So far, general circulation models (GCMs) have performed poorly in the simulation of monsoon intraseasonal variability. Atmospheric GCMs exhibit a variety of biases such as an absence of northward propagation (Kemball-Cook et al. 2002) and a small intraseasonal variability in the Indian Ocean, particularly in its equatorial portion (Kang et al. 2002; Waliser et al. 2003; Zheng et al. 2004). Coupled GCMs have achieved better results in terms of large-scale organization and amplitude of this variability (Kemball-Cook et al. 2002; Fu and Wang 2004b; Fu and Wang 2004a; Ra- 
jendran et al. 2004; Rajendran and Kitoh 2006; Zheng et al. 2004) as well as in terms of predictability (Fu et al. 2007). These results are similar to the one obtained in the GCM simulations of the Madden-Julian oscillation (MJO): most coupled models perform better than their forced atmospheric component (Flatau et al. 1997; Inness and Slingo 2003; Rajendran and Kitoh 2006; Woolnough et al. 2007; Watterson and Syktus 2007) with a few exceptions (e.g., Hendon 2000). In these studies, the SST anomalies tend to reduce the anomalies of turbulent surface heat flux (Shinoda et al. 1998).

Nevertheless, simulation of the intraseasonal activity remains one of the GCMs' main weaknesses as far as tropical precipitation is concerned (Dai 2006). This limit to GCM skill is an obstacle to subseasonal (10 days to a month in advance) and seasonal forecasting, as well as to climate prediction. Understanding the mechanisms of the monsoon intraseasonal variability is therefore an ongoing challenge. Considering their impact on the GCM simulations, the ocean-atmosphere coupled mechanisms are of particular interest. In the present work, we study these mechanisms in a model that is simple by comparison to a GCM. Because of its relative simplicity, we can analyze the mechanisms operating in the model in a more detailed and complete manner than is possible in a GCM. Our study provides a complementary perspective to that of GCM and observational studies.

Spectra of the observed monsoon variability show two significant peaks in the intraseasonal range: one at 10-20 days and one at 30-60 days (Goswami 2005). The 10-20-day mode seems to be associated with disturbances propagating from the Pacific warm pool to South Asia that appear as Rossby waves deviated poleward by the mean monsoon flow (Chatterjee and Goswami 2004). On the other hand, the 30-60-day mode is associated with northward propagation of the tropical convergence zone (TCZ) from its preferred equatorial position to its preferred monsoon location around $20^{\circ} \mathrm{N}$ (Sikka and Gadgil 1980). The SST signal associated with the latter mode is well documented: the SST anomaly leads the precipitation by about 10 days (Vecchi and Harrison 2002; Goswami 2005; Wang et al. 2006; Roxy and Tanimoto 2007; Sengupta et al. 2001) and is maximum in the Bay of Bengal (BoB) and the western subtropical Pacific (Vecchi and Harrison 2002; Duvel and Vialard 2007).

In terms of mechanisms, the 30-60-day mode is essentially atmospheric, resulting from the interaction of atmospheric dynamics and convection. The northward propagation of the precipitation is caused by atmospheric boundary-layer convergence north of the maximum of convection (Lawrence and Webster 2002; Gos- wami 2005). This convergence is in turn caused by a barotropic maximum of vorticity throughout the free troposphere via Coriolis acceleration (Jiang et al. 2004; Goswami 2005). The mechanisms responsible for this maximum of vorticity are still debated. Jiang et al. proposed the "vertical shear mechanism" that explains the creation of vorticity by the asymmetry of the anomalous vertical advection of the mean baroclinic zonal momentum with respect to the center of convection. This mechanism is at play in a simple, quasi-linear model (Drbohlav and Wang 2005). On the other hand, Bellon and Sobel (2008a,b, hereafter BSa and BSb) used an idealized, axisymmetric model in its nonlinear (BSa) and linear (BSb) versions to simulate the northwardpropagating intraseasonal oscillation. It appeared that, in their model, although the "vertical shear mechanism" contributes to the instability of the mean monsoon flow and the northward propagation, the crucial mechanism relies on the advection of anomalous baroclinic vorticity by the mean baroclinic flow. BSa and $\mathrm{BSb}$ also studied the role of the turbulent surface heat fluxes, finding that interactive variations in these fluxes have a strong destabilizing effect on the intraseasonal mode and that they slow down its northward propagation.

On the other hand, observational studies (Roxy and Tanimoto 2007) have shown that the intraseasonal variations of the shortwave radiation at the surface are of the same magnitude as those of the turbulent fluxes. These variations are associated to changes in cloudiness. Perturbations of the cloud radiative forcing (CRF) are therefore likely to have an impact on the northward propagating oscillation, as in the case of the winter MJO (Woolnough et al. 2000; Lin and Mapes 2004; Watterson 2002). The importance of both turbulent and shortwave surface fluxes suggests the possible importance of the oceanic response and feedback.

In the present work, we use the atmospheric model of BSb coupled to a simple, linear model of the upper ocean to investigate the role of the ocean-atmosphere coupling in the monsoon intraseasonal oscillation. The role of the clouds and ocean dynamics are investigated. Section 2 describes the model, and section 3 investigates the oceanic response and its feedback on the atmosphere. Section 4 investigates the sensitivity of the coupled systems to changes of the oceanic mixed layer depth before a discussion in section 5 .

\section{Linear model}

\section{a. Summary of the atmospheric model}

The atmospheric model used here is the second Quasi-Equilibrium Tropical Circulation Model 

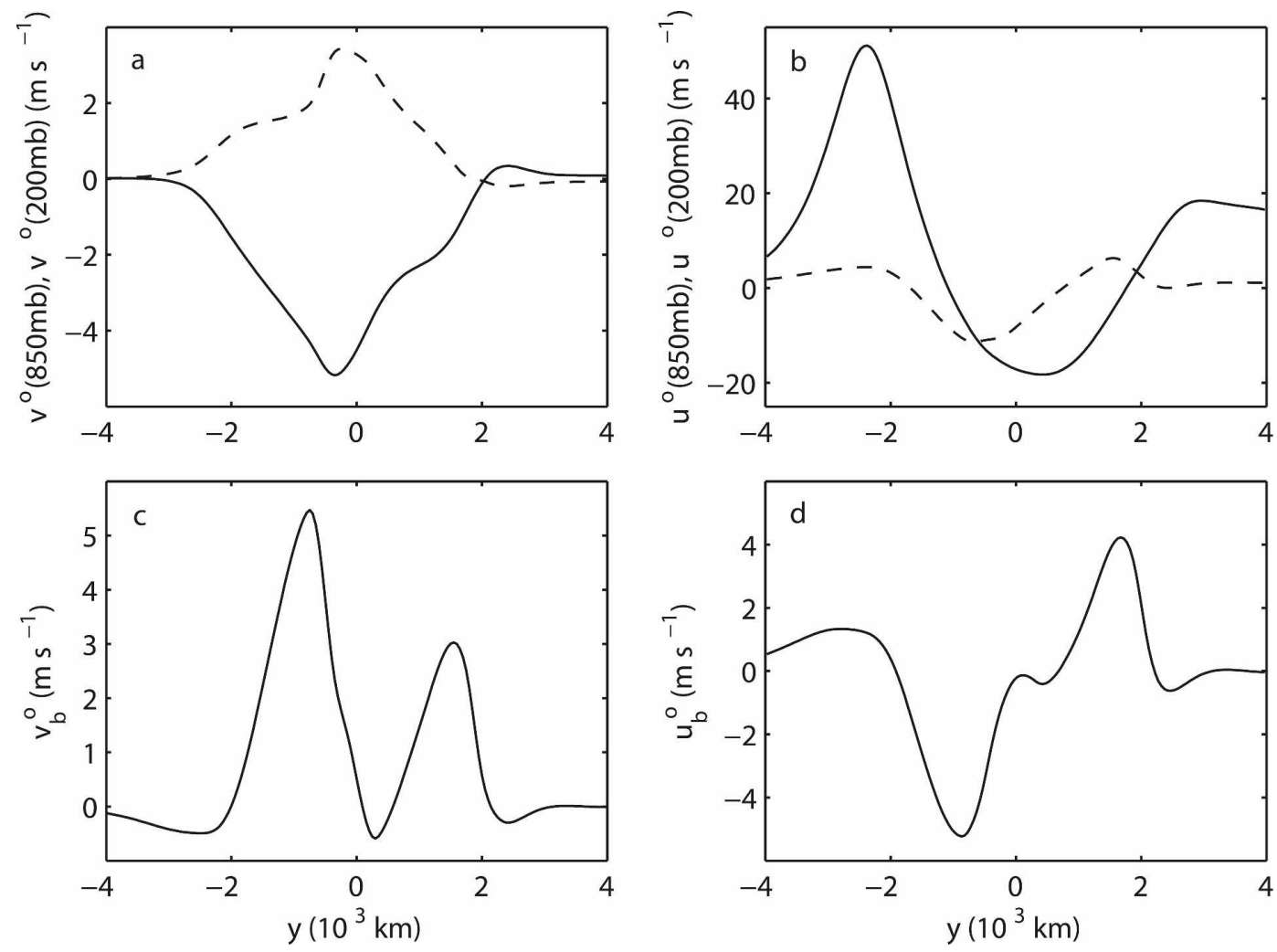

FIG. 1. Mean state of the model in the control case: (a) meridional wind at $200 \mathrm{mb}$ (solid) and $850 \mathrm{mb}$ (dashed), (b) zonal wind at $200 \mathrm{mb}$ (solid) and $850 \mathrm{mb}$ (dashed), ABL (c) meridional wind and (d) zonal wind (solid).

(QTCM2) developed by Sobel and Neelin (2006). The QTCM family of models is based on the Galerkin projection of the primitive equations on a limited number of reference vertical profiles derived from asymptotic solutions of the quasi-equilibrium theory. In the QTCM1 (Neelin and Zeng 2000; Zeng et al. 2000), the vertical structure of the wind has two degrees of freedom (one barotropic mode $\mathbf{v}_{0}$ and one baroclinic mode $\mathbf{v}_{1}$ ) and the thermodynamical variables have each one degree of freedom (temperature $T_{1}$ and humidity $q_{1}$ ). The QTCM2 includes a well-mixed atmospheric boundary layer $(\mathrm{ABL})$ of fixed depth that adds another degree of freedom for both dynamical and thermodynamical variables (wind $\mathbf{v}_{b}$, dry static energy $s_{b}$, and humidity $q_{b}$ ).

This model is used here in an axisymmetric equatorial $\beta$-plane configuration with simplified physical parameterizations as in $\mathrm{BSa}$ and $\mathrm{BSb}$. In particular, shallow convection is neglected and deep convection is parameterized by a simple Betts-Miller scheme (Sobel and Neelin 2006). Radiation is very simply represented as well: clear-sky radiative cooling is parameterized by a Newtonian relaxation back to a latitudinally uniform temperature profile, and only the cloud radiative forc- ing associated with convective clusters is parameterized (this is the only difference with the model used in BSb, where no CRF was represented). The combined shortwave-longwave forcing is parameterized as a transfer of energy from the ocean to the free troposphere. This parameterization is detailed in section $2 \mathrm{c}$.

We use the linearized QTCM2, whose equations, as well as a description of the atmospheric mechanisms of the intraseasonal oscillation, can be found in BSb. In these equations, the SST anomalies appear only in the humidity and heat budget of the ABL: the anomalous SSTs cause an additional term in the turbulent fluxes described in section $2 \mathrm{c}$, and the radiation is considered to relax the (anomalous) ABL potential temperature toward the (anomalous) SST with a time scale of 5 days.

The atmospheric base state is taken as the time mean of the oscillatory solution simulated by the nonlinear model in BSa (i.e., without CRF). This base state reproduces the main characteristics of the Asian monsoon: a strong asymmetric Hadley circulation with a reversal of the trade winds in the northern tropics and two TCZs, one over the equator and the other in the monsoon trough around $20^{\circ} \mathrm{N}$. This mean state is shown in Figs. 1 and 2. 

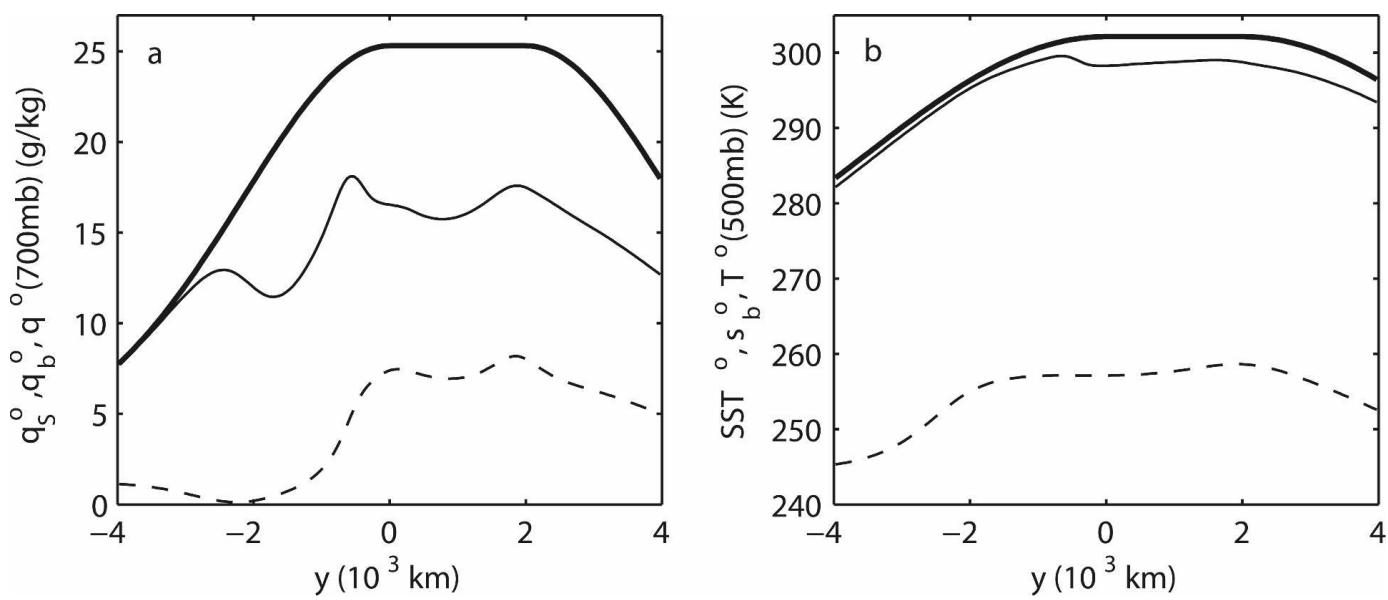

FIG. 2. Mean state of the model in the control case: (a) saturation humidity at the SST (thick), ABL humidity (solid), and free-tropospheric humidity (at $700 \mathrm{mb}$, dashed); (b) SST (thick), ABL (solid), and free-tropospheric (at $500 \mathrm{mb}$, dashed) temperatures.

Note that $1^{\circ}$ of latitude corresponds to about $100 \mathrm{~km}$ on the equatorial $\beta$ plane, and the latitude will be hereafter indicated either in degrees or distance units.

\section{b. Oceanic model}

The upper-ocean model consists of an oceanic mixed layer (OML) of variable depth $H_{o}$, within which the temperature $T_{s}$ and velocity $\mathbf{v}_{o}$ are assumed to be uniform in the vertical. This model allows one to study the thermodynamic response of the ocean as well as the effect of upwelling. The model is linearized about a state of rest in which $T_{s}$ is the fixed SST field used in $\mathrm{BSa}$ and $\mathrm{BSb}$, uniform $\left(29^{\circ} \mathrm{C}\right)$ between the equator and about $20^{\circ} \mathrm{N}$, with sinusoidal decrease poleward of this region. This mean state is shown in Fig. 2b. A sensitivity experiment using the observed mean SST averaged over the longitudes of the Bay of Bengal yielded results not significantly different from those shown below. We also neglect the mean seasonal circulation of the ocean. We believe that, while this circulation is crucial to establish the mean SST field, its effect on the dynamics of the intraseasonal oscillation is small.

The heat budget of the OML gives the equation for the SST perturbation $T_{s}^{\prime}$ :

$$
\partial_{t} T_{s}^{\prime}+\mathbf{v}_{o}^{\prime} \nabla \bar{T}_{s}+w_{e}^{\prime} \frac{\overline{\Delta T}_{o}}{\bar{H}_{o}}=-\frac{Q_{0}^{\prime}-Q_{-H_{o}}^{\prime}}{C_{o}}+k_{o} \nabla^{2} T_{s}^{\prime},
$$

where the overbar indicates the basic state and the prime indicates the perturbation from this basic state. Here $w_{e}^{\prime}$ is the perturbation of the entrainment of subsurface water and $\overline{\Delta T}_{o}=\bar{T}_{s}-\bar{T}_{o}$ is the seasonal difference of temperature between the mixed layer and the subsurface waters: $\bar{T}_{o}$ is considered to be steady at intraseasonal time scales; $k_{o}$ is the horizontal diffusivity coefficient; $C_{o}=\rho_{w r} C_{w} \bar{H}_{o}$ is the heat capacity of the OML in the base state, with $\rho_{w r}$ the reference density of water and $C_{w}$ the heat capacity of water; $Q_{0}^{\prime}$ and $Q_{-H_{o}}^{\prime}$ are the anomalous upward total heat fluxes at the surface and at the OML bottom. At the surface

$$
Q_{0}^{\prime}=E^{\prime}+H^{\prime}+R_{0}^{\prime},
$$

where $E^{\prime}, H^{\prime}$, and $R_{0}^{\prime}$ are the perturbations of, respectively, the upward latent heat, sensible heat and radiative fluxes.

The mass budget of the OML gives the time evolution of the mixed layer depth (MLD):

$$
\partial_{t} H_{o}^{\prime}+\nabla \cdot\left(\bar{H}_{o} \mathbf{v}_{o}^{\prime}\right)=w_{e}^{\prime},
$$

and the momentum budget of the OML in the Boussinesq approximation is

$$
\begin{aligned}
\partial_{t} \mathbf{v}_{o}^{\prime}+f \mathbf{k} \times \mathbf{v}_{o}^{\prime}= & -\frac{1}{\rho_{w r}} \nabla\left\langle p^{\prime}\right\rangle^{o}+\epsilon_{b} \mathcal{M}_{o}^{a}\left(\mathbf{v}_{b}^{\prime}-\overline{\mathbf{v}}_{b} \frac{H_{o}^{\prime}}{\bar{H}_{o}}\right) \\
& +k_{o} \nabla^{2} \mathbf{v}_{o}^{\prime},
\end{aligned}
$$

where $p$ is the pressure and $\langle\cdot \cdots\rangle^{o}$ indicates the average over the OML. In (4), $\mathcal{M}_{o}^{a}$ accounts for the ratio of the ABL mass to the OML mass: $\mathcal{M}_{o}^{a}=p_{B} / g / \rho_{w r} / \bar{H}_{o}$, where $p_{B}$ is the pressure depth of the ABL and $g$ is the gravitational acceleration.

The mean pressure across the OML is computed using the equation of state of water in which the variations of salinity are neglected: $\rho_{w}=\rho_{w r}\left[1-\alpha\left(T_{s}-\right.\right.$ $\left.T_{s 0}\right)$ ], with $\alpha$ the thermal expansion coefficient. Integrating the hydrostatic equation from the deep ocean, 
where the pressure gradients are assumed negligible, yields

$$
\begin{aligned}
\frac{1}{\rho_{w r}} \nabla\left\langle p^{\prime}\right\rangle^{o}= & \alpha g\left(\frac{\bar{H}_{o}}{2} \nabla T_{s}^{\prime}+\nabla \bar{H}_{o} T_{s}^{\prime}+\frac{\boldsymbol{\nabla} \bar{T}_{s}}{2} H_{o}^{\prime}\right. \\
& \left.+\overline{\Delta T}_{o} \nabla H_{o}^{\prime}\right) .
\end{aligned}
$$

\section{c. Turbulent surface fluxes}

Variations in turbulent surface fluxes contribute strongly to the instability of the atmospheric mode (BSb). Turbulent fluxes also compose a large fraction of the enthalpy transfer between ocean and atmosphere and are, therefore, expected to be modulated by oceanatmosphere coupling. We parameterize them using linearized "bulk formulae":

$$
\begin{aligned}
E^{\prime}= & \rho_{a} C_{D}\left[\overline{\mathbf{v}}_{b} \cdot \mathbf{v}_{b}^{\prime} \bar{V}_{s}^{-1}\left(q^{*}\left(\bar{T}_{s}\right)-\bar{q}_{b}\right)\right. \\
& \left.+\bar{V}_{s}\left(\frac{d q^{*}}{d T}\left(\bar{T}_{s}\right) T_{s}^{\prime}-q_{b}^{\prime}\right)\right], \\
H^{\prime}= & \rho_{a} C_{D}\left[\overline{\mathbf{v}}_{b} \cdot \mathbf{v}_{b}^{\prime} \bar{V}_{s}^{-1}\left(C_{p} \bar{T}_{s}-\bar{s}_{b}\right)+\bar{V}_{s}\left(C_{p} T_{s}^{\prime}-s_{b}^{\prime}\right)\right],
\end{aligned}
$$

where $\rho_{a}$ is the density of surface air, $C_{D}$ the drag coefficient, $C_{p}$ the heat capacity of air at constant pressure, $q^{*}$ the saturation specific humidity at $\bar{T}_{s}$ (in energy units, i.e., multiplied by the latent heat of vaporization $L_{v}$ ), and $d q^{*} / d T$ its change with temperature; $V_{s}$ is the surface wind speed:

$$
V_{s}=\sqrt{G^{2}+\left|\mathbf{v}_{b}\right|^{2}},
$$

where $G$ is the gustiness, a constant wind that accounts for subgrid circulations. The first terms on the righthand side of Eqs. (6) and (7) are the wind-induced components, and the second terms are the air-sea gradient components.

\section{d. Radiation}

We can decompose the radiative surface flux into its longwave and shortwave components:

$$
R_{0}=L_{0}-S_{0},
$$

where $L_{0}$ is the net upward longwave surface flux and $S_{0}$ is the net downward solar surface flux.

The perturbation of the longwave surface flux $L_{0}^{\prime}$ is parameterized by a simple Newtonian relaxation on the SST:

$$
L_{0}^{\prime}=\epsilon_{T} T_{s}^{\prime}
$$

with $\epsilon_{T}=6.3 \mathrm{~W} \mathrm{~m}^{-2} \mathrm{~K}^{-1}$ (Neelin and Zeng 2000). This neglects the perturbation greenhouse effect in that it is independent of atmospheric temperature, humidity, and cloudiness. This effect appears negligible at intraseasonal time scales (Sengupta et al. 2001; Roxy and Tanimoto 2007). This parameterization is arguably inconsistent with the atmospheric model, in particular with the parameterization for radiative cooling in the ABL. The latter has a term dependent on ABL temperature, and the most physical assumption would be that the radiative flux divergence associated with this term results from perturbation fluxes into the surface as well as the free troposphere. Sensitivity studies in which the atmospheric and oceanic radiative parameterizations were made completely consistent showed no significant differences with those presented here, indicating that this minor inconsistency is of no consequence for our results.

The net downward solar flux within the ocean can be written (Duvel et al. 2004)

$$
S(z)=S_{0}\left[(1-\Sigma) e^{\gamma_{0} z}+\Sigma e^{\gamma z}\right],
$$

where $z$ is the altitude, $\Sigma$ is the ratio of penetrating solar radiation, and $\left(\gamma_{0}, \gamma\right)$ are the rates of decay with depth of the solar radiation, characteristic of tropical openocean clear water. For (11), $\gamma_{0}^{-1}$ corresponds to $30 \mathrm{~cm}$ and $(1-\Sigma) S_{0}$ is therefore absorbed in a thin layer right at the surface. On the other hand, $\gamma^{-1}$ corresponds to about $25 \mathrm{~m}$, and $\Sigma S_{0}$ penetrates through the rest of the OML to the extinction depth. The thinning and deepening of the OML thus causes variations of the solar flux at the bottom of the OML:

$$
Q_{-H_{o}}^{\prime}=\gamma H_{o}^{\prime} \Sigma \bar{S}_{0} e^{-\gamma \bar{H}_{o}},
$$

where we neglect the intraseasonal variations of $S_{0}$ (which are mostly related to cloudiness). Sensitivity studies showed that this simplification does not change our results.

If we consider the surface layer in which the nonpenetrating (near-infrared) solar flux is absorbed as infinitely thin, we can neglect its heat capacity. The surface longwave flux at the bottom of this layer is negligible, and the heat budget of this surface layer can thus be written

$$
H_{0^{-}}-\Sigma S_{0}-Q_{0}=0,
$$

where $H_{0^{-}}$is the sensible heat flux due to oceanic turbulence at the bottom of the surface layer (i.e., just below the surface). This relationship will be useful in the next section.

The cloud radiative forcing is limited to the effect of convective ensembles. This forcing is very small at the 
top of the atmosphere: the cloud greenhouse effect compensates the screening of solar radiation ( $\mathrm{Ra}-$ manathan et al. 1989). Lin and Mapes (2004) showed that this balance is only a rough approximation in the case of the intraseasonal oscillation, but we ignore the discrepancies to keep our model simple. This forcing can be simply parameterized as a cooling of the OML proportional to the precipitation $P^{\prime}$ (Bretherton and Sobel 2002). The resulting perturbation of shortwave surface flux is

$$
S_{0}^{\prime}=-r P^{\prime},
$$

with $r=0.15$, consistent with Lin and Mapes (2004) and Bretherton and Sobel (2002). The atmospheric model is also modified to include the $\mathrm{CRF}$ as an equivalent warming $r P^{\prime}$ of the free troposphere.

\section{e. Closure on the entrainment}

Following Niiler and Kraus (1977), the entrainment at the bottom of the OML is parameterized by a closure on the budget of turbulent kinetic energy of the OML. The reader is invited to refer to the original article for details about the main simplifications involved in the closure. For regions in which the upward buoyancy flux at the surface is positive (such as the tropical Indian Ocean), the nonlinear equation is

$$
\begin{aligned}
w_{e} H_{o} \Delta b_{o}= & 2 m_{s} u^{*^{3}}+m_{b} H_{o} B_{0^{-}} \\
& -\left(H_{o}-\frac{2}{\gamma}\right) \frac{\alpha g}{\rho_{w r} C_{w}} \Sigma S_{0},
\end{aligned}
$$

where $\Delta b_{o}$ is the buoyancy jump at the bottom of the OML, $m_{s}$ is the coefficient associated with the mixing due to wind stirring, and $m_{b}$ is the mixing coefficient associated to the sink of buoyancy at the surface; $u^{*}$ is the friction velocity,

$$
u^{*^{2}}=\rho_{a} / \rho_{w r} C_{D} \mathrm{~V}_{s}^{2}
$$

and $B_{0^{-}}$is the upward oceanic turbulent flux of buoyancy just below the surface. If the effect of salinity is neglected, it is proportional to the oceanic turbulent heat flux and, according to Eq. (12), can be expressed in terms of $Q_{0}$ and $S_{0}$ :

$$
B_{0^{-}}=\frac{\alpha g}{\rho_{w r} C_{w}} H_{0^{-}}=\frac{\alpha g}{\rho_{w r} C_{w}}\left(\Sigma S_{0}+Q_{0}\right) .
$$

The left-hand side of Eq. (14) corresponds to the destruction of turbulent kinetic energy by entrainment

\begin{tabular}{|c|c|c|}
\hline Parameter & Value & Definition \\
\hline$C_{w}$ & $4100 \mathrm{~J} \mathrm{~kg}^{-1} \mathrm{~K}^{-1}$ & Specific heat of seawater \\
\hline$\rho_{w r}$ & $1028 \mathrm{~kg} \mathrm{~m}^{-3}$ & Reference density of seawater \\
\hline$\alpha$ & $3.10^{-4} \mathrm{~K}^{-1}$ & Coefficient of thermal expansion \\
\hline $\bar{S}_{0}$ & $270 \mathrm{~W} \mathrm{~m}^{-2}$ & Solar radiation at the surface \\
\hline$\Sigma$ & 0.45 & $\begin{array}{l}\text { Fraction of penetrating surface } \\
\text { radiation }\end{array}$ \\
\hline$\gamma_{0}$ & $3 \mathrm{~m}^{-1}$ & $\begin{array}{l}\text { Attenuation coefficient of the } \\
\text { nonpenetrating solar radiation }\end{array}$ \\
\hline$\gamma$ & $0.04 \mathrm{~m}^{-1}$ & $\begin{array}{l}\text { Attenuation coefficient of the } \\
\text { penetrating solar radiation }\end{array}$ \\
\hline$m_{s}$ & 1.2 & $\begin{array}{l}\text { Coefficient of mixing due to } \\
\text { wind stirring }\end{array}$ \\
\hline$m_{b}$ & 0.2 & $\begin{array}{l}\text { Coefficient of mixing due to } \\
\text { surface buoyancy flux }\end{array}$ \\
\hline$k_{o}$ & $4 \times 10^{4} \mathrm{~m}^{2} \mathrm{~s}^{-1}$ & Oceanic diffusivity \\
\hline
\end{tabular}
of dense subsurface waters. The first term on the righthand side corresponds to the power of wind stirring, while the two last terms on that side correspond to the
TABLE 1. Model parameter values.

creation of potential energy by, respectively, the surface fluxes and the penetrating solar radiation.

Linearizing Eq. (14) around a state of rest yields

$w_{e}^{\prime} \bar{H}_{o} \overline{\Delta b}_{o}=m_{s}^{\prime} \overline{\mathrm{V}}_{s} \overline{\mathbf{v}}_{b} \cdot \mathbf{v}_{b}^{\prime}+m_{b} \bar{H}_{o} B_{0}^{\prime}-\left(m_{b} \bar{B}_{0^{-}}-J_{0}\right) H_{o}^{\prime}$,

with

$$
m_{s}^{\prime}=6 m_{s}\left(\frac{\rho_{a}}{\rho_{w r}} C_{D}\right)^{3 / 2}
$$

and

$$
J_{0}=\frac{\alpha g}{\rho_{w r} C_{w}} \Sigma \bar{S}_{0}:
$$

$B_{0^{-}}^{\prime}$ is computed from $Q_{0}^{\prime}$ and $S_{0}^{\prime}$ using Eq. (15). The parameters $\overline{\Delta T}_{o}, \overline{\Delta b}_{o}, \bar{H}_{o}$, and $\bar{S}_{0}$ (and, consequently, $J_{0}$ ) can be functions of latitude; in practice, they are set to empirically determined values. Using Eq. (15) and the energy balance of the basic-state OML $\left[\bar{Q}_{0}+\Sigma \bar{S}_{0} \exp \left(-\gamma \bar{H}_{\mathrm{o}}\right)\right]=0, \bar{B}_{0^{-}}$can be related to $J_{0}$ :

$$
\bar{B}_{0^{-}}=J_{0}\left(1-e^{-\gamma \bar{H}_{o}}\right) .
$$

\section{f. Method and prefatory results}

The parameters for the atmospheric model can be found in BSa and BSb, and Table 1 gives the parameters for the ocean model used in this paper.

The equations of the model are discretized over a domain of $20000 \mathrm{~km}(10000 \mathrm{~km}$ in each hemisphere) with a spatial resolution of $50 \mathrm{~km}$ (400 grid points). The Jacobian matrix of the model is computed, using the specified base state. The eigenvalues and eigenvectors are then numerically computed. In such an eigenmode, 
the time evolution of a variable $X$ can be expressed as follows:

$$
X(y, t)=\operatorname{Re}\left\{N_{X}(y) e^{\lambda t}\right\}=\mathcal{A}_{X}(y) \cos \left[\omega t-\phi_{x}(y)\right] e^{\Gamma t},
$$

where $y$ is the latitude, $N_{X}(y)$ is the component of the complex eigenmode related to $X$, and $\lambda$ is the associated complex eigenvalue (with positive imaginary part); $\mathcal{A}_{X}=\left|N_{X}\right|$ is the amplitude of $X, \phi_{X}=-\arg \left(N_{X}\right)$ is its phase; $\omega=\operatorname{Im}(\lambda)$ is the frequency of the mode, and $\Gamma=\operatorname{Re}(\lambda)$ is its growth rate. The period of the mode is $\mathcal{T}=2 \pi /|\omega|$ and $\tau_{e}=|\Gamma|^{-1}$ is its $e$-folding time. Note that the amplitude $\mathcal{A}_{X}(y)$ can be rescaled simply by changing the time origin; thus, it contains information only on the latitudinal modulation of the amplitude. Here, we scale the amplitudes of the different variables so that the precipitation amplitude of the linear mode is comparable to that of the nonlinear oscillation. The precipitation amplitude is scaled so that its maximum equals that of the first harmonic of the nonlinear oscillation. The phase lag $\phi_{X}(y)$ provides information on the direction of propagation: for a positive $\omega$, an increase of $\phi_{X}$ with latitude indicates northward propagation of $X$.

BSa showed that the full nonlinear atmospheric model without CRF has two very similar limit cycles comparable to the observed intraseasonal oscillation of the Asian summer monsoon, with periods of about 50 days and the distinctive northward propagation of the TCZ. Figure 3 a shows the time evolution of the precipitation anomaly in the first limit cycle. The precipitation amplitude is about $5 \mathrm{~mm}$ day $^{-1}$ for most of the propagation, as in the observations (Roxy and Tanimoto 2007). The maximum of precipitation variability around $20^{\circ} \mathrm{N}$ is quite large compared to the observations in the north of the Indian Ocean. This bias of our model results, in part, from the aquaplanet configuration that allows an unrealistically large humidity supply from the region north of $20^{\circ} \mathrm{N}$ to the monsoonal TCZ.

The same model, linearized about the mean state of the first limit cycle (i.e., the atmospheric model used in the present work, with $r=0$ ), has one unstable eigenmode with a period and structure similar to the nonlinear oscillation. Figure $3 \mathrm{~b}$ shows the oscillatory component of the precipitation $\mathcal{A}_{P}(y) \cos \left[\omega t-\phi_{P}(y)\right]$ in this mode. The main characteristics of the nonlinear oscillation (northward propagation, maxima of amplitude) are preserved. BSb studied the atmospheric mechanisms responsible for this linearly unstable mode and showed the importance of the mean meridional baroclinic flow in the instability and scale selection. Furthermore, surface fluxes, and in particular their windinduced variations, were also shown to play a role in
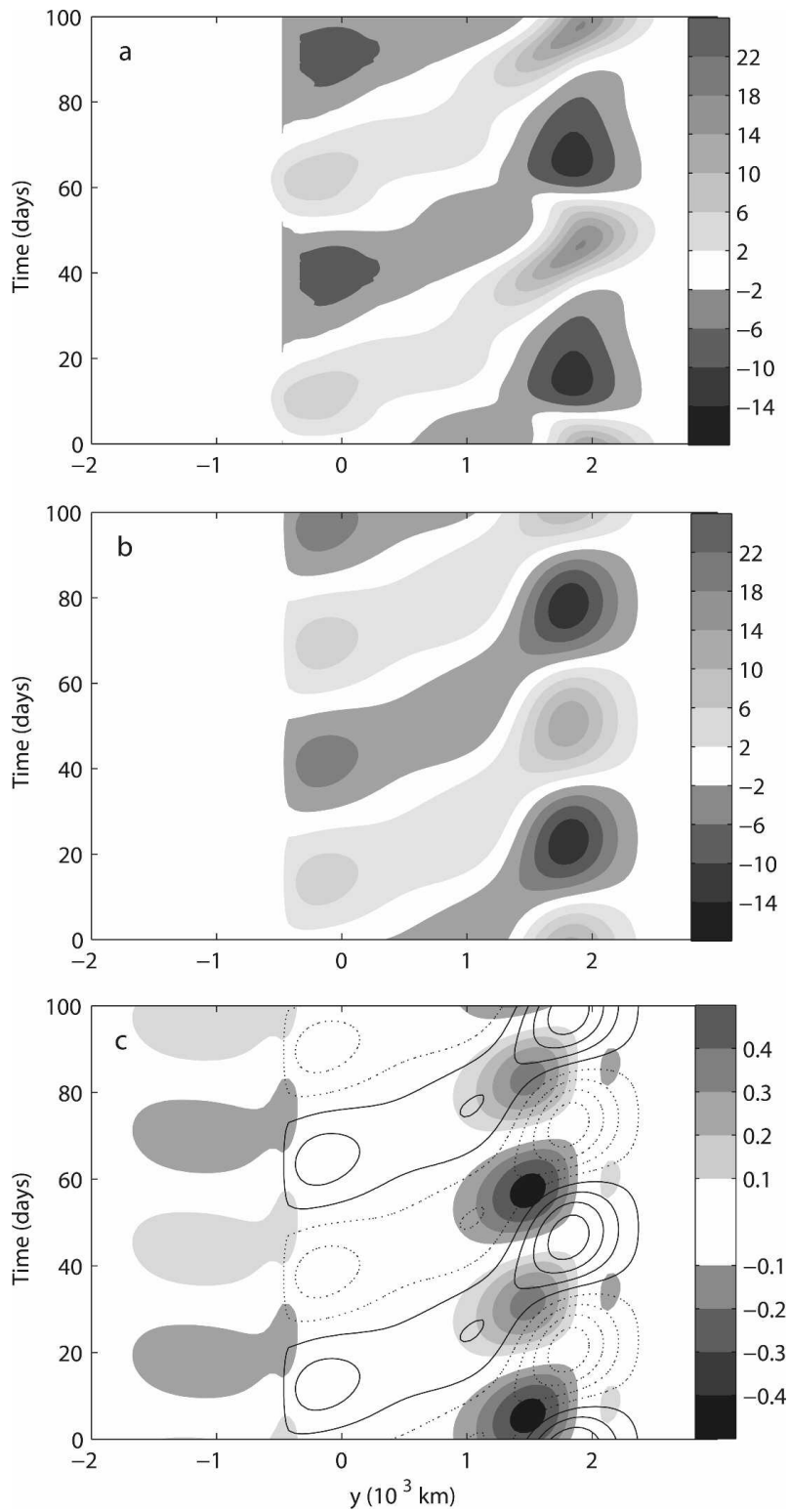

FIG. 3. Precipitation anomaly $\left(\mathrm{mm} \mathrm{day}^{-1}\right)$ in (a) the nonlinear oscillation and (b) the linear, uncoupled, atmospheric mode; (c) SST anomaly (shaded) and precipitation anomaly (solid/dotted contours for positive/negative values) in the coupled mode.

destabilizing the mean flow and in slowing down the oscillation. How an interactive ocean responds to and modulates this mode is the focus of the present work.

When the CRF is included $(r=0.15)$, the uncoupled linear mode has a period of 67.9 days and an $e$-folding time of 15.6 days. The structure of the mode is very similar to that of the case studied in BSb except for a reduced precipitation amplitude at the equator due to the destabilizing "rich-get-richer" effect of the cloudinduced radiative perturbations (Bretherton and Sobel 
2002; Sobel et al. 2004; Neelin et al. 2003; Chou and Neelin 2004; Raymond 2000) on the interaction between dynamics and convection.

\section{Coupled oscillation}

Our aquaplanet, axisymmetric configuration excludes the dynamical processes related to the presence of non-zonally uniform conditions such as the continent. In particular, our model cannot be applied satisfactorily to the Arabian Sea sector where the coastal upwelling off the coasts of Somalia and Oman largely controls the SST signals. Our model is more suitable to represent longitudes corresponding to the $\mathrm{BoB}$, and to some extent to the west Pacific, where the SST patterns depend only weakly on longitude. Here we choose conditions close to the BoB summer mean as the oceanic base state.

\section{a. Control case}

In the $\mathrm{BoB}$, the summer temperature stratification is weak in the upper ocean (first $50 \mathrm{~m}$ ) and almost independent of latitude. In this isothermal layer, some warm or barrier layers can develop, and the stratification is mostly controlled by salinity. The Ganges delta and the intense monsoon precipitation constitute a large input of freshwater into the northern BoB. In the seasonal average, this freshwater creates a shallow mixed layer (about $30 \mathrm{~m}$ ) along the northern coast. Its influence diminishes away from the coast, and the seasonally averaged OML layer deepens monotonically southward down to the southern extratropics, where its depth reaches 100-150 m (de Boyer Montégut et al. 2004).

We now include this observed feature in our model by setting the basic-state MLD and subsurface temperature to the following latitude-dependent profiles:

$$
\bar{H}_{o}= \begin{cases}120, & y<-6000 \mathrm{~km} \\ 60-30 \times y / \sigma_{o}, & -6000 \mathrm{~km}<y<3000 \mathrm{~km} \\ 15, & y>3000 \mathrm{~km},\end{cases}
$$

where $\sigma_{o}=2000 \mathrm{~km}$, and

$$
\overline{\Delta T}_{o}= \begin{cases}\delta T_{o}, & \bar{H}_{o}<H_{c} \\ \delta T_{o}+\zeta \times\left(\bar{H}_{o}-H_{c}\right), & \bar{H}_{o}>H_{c},\end{cases}
$$

where $\delta T_{o}=0.5 \mathrm{~K}, \quad \zeta=0.1 \mathrm{~K} \mathrm{~m}^{-1}$, and $H_{c}=50 \mathrm{~m}$. This latitude-dependent profile implies that the tem-
TABLE 2. Period $\mathcal{T}$ and $e$-folding time $\tau_{e}$ of the unstable mode in the different experiments.

\begin{tabular}{lcc}
\hline \multicolumn{1}{c}{ Case } & $\mathcal{T}$ (days) & $\tau_{e}$ (days) \\
\hline Uncoupled & 67.9 & 15.6 \\
No dynamics & 54.5 & 15.4 \\
Coupled & 50.8 & 17.7 \\
No CRF & 48.0 & 71.9 \\
\hline
\end{tabular}

perature of the subsurface waters has the same latitudinal structure as the basic-state SST. This is verified in the observations (de Boyer Montégut et al. 2004). The buoyancy jump at the OML bottom is set to $\overline{\Delta b}_{o}=$ $\left(2 \times 10^{-3} \mathrm{~m} \mathrm{~s}^{-2}\right): \overline{\Delta b}_{o}$ is exclusively due to a salinity jump at the OML bottom in the BoB (where $\bar{H}_{o}<$ $50 \mathrm{~m}$ ) and it is a very simple way to represent the combined effect of salinity and temperature jumps where $\bar{H}_{o}>50 \mathrm{~m}$. The variation of the base-state surface insolation with latitude is neglected and $\bar{S}_{0}$ is set to a typical tropical value of $270 \mathrm{~W} \mathrm{~m}^{-2}$.

In this configuration, the model has one unstable eigenmode with a period of 50.8 days, about $25 \%$ shorter than uncoupled period, and an $e$-folding time of 17.7 days, similar to the uncoupled case. Oceanic processes therefore accelerate the northward propagation significantly. The periods and $e$-folding times in the different experiments performed in this study are recorded in Table 2. Figure 4 shows the precipitation structure in terms of the amplitude $\mathcal{A}_{P}$ and phase $\phi_{P}$ for both coupled and uncoupled modes. The precipitation pattern is very similar in the two cases, featuring northward propagation $\left(\phi_{P}\right.$ increases with latitude) toward a strong amplitude maximum in the monsoon TCZ around $20^{\circ} \mathrm{N}$.

The oscillating components of SST and precipitation in the coupled mode are shown in Fig. 3c. The SST anomalies are almost in quadrature with the precipitation anomalies. The maximum SST amplitude occurs around $15^{\circ} \mathrm{N}$, just south of the monsoonal precipitation maximum at $20^{\circ} \mathrm{N}$. This is in agreement with observations that SST variability maximizes at this magnitude $(0.8 \mathrm{~K})$ in the north of the BoB and leads precipitation by about 10 days (Bhat et al. 2001; Sengupta et al. 2001; Vecchi and Harrison 2002; Wang et al. 2006; Roxy and Tanimoto 2007). The SST warms during monsoon breaks and cools during active phases. There is a secondary maximum of SST amplitude, in the nonprecipitating Southern Hemisphere, whose equatorward flank is nearly in quadrature with the convection at the equator.

Figure 5 shows the amplitudes and phases of the SST and MLD. The northward propagation of SST anoma- 

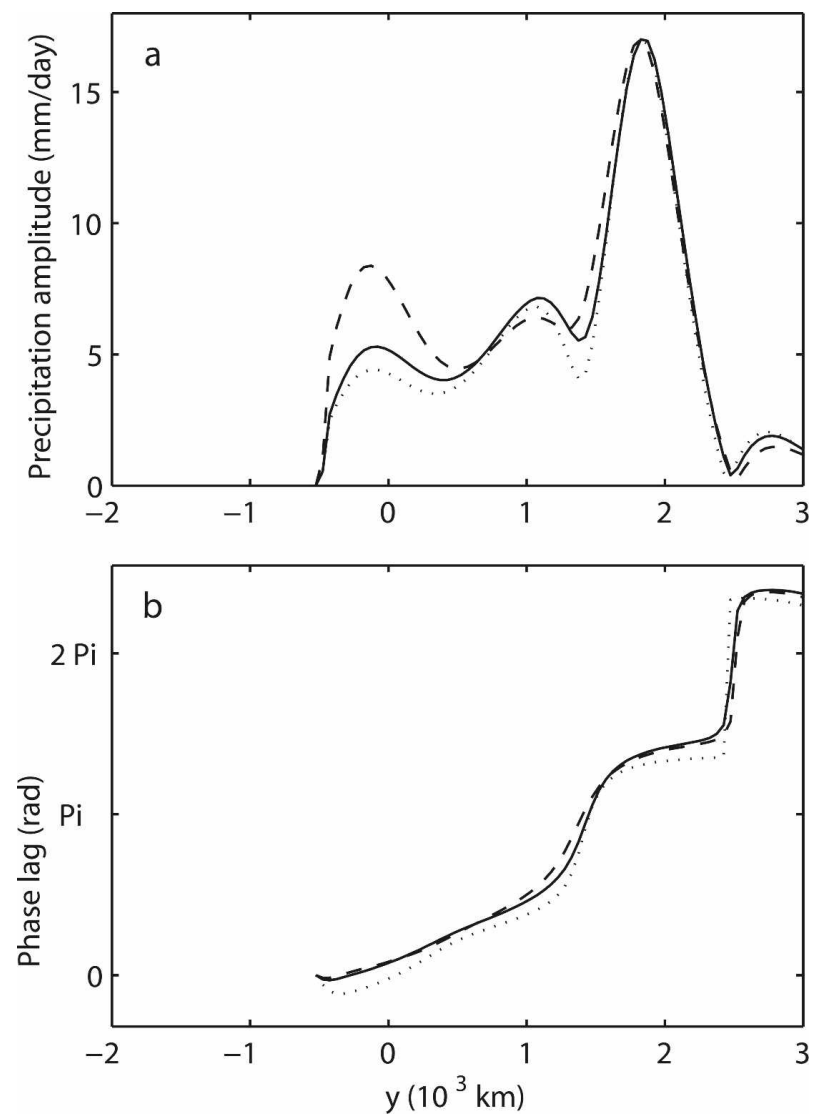

FIG. 4. (a) Amplitude and (b) phase of the precipitation the uncoupled mode (dotted), the coupled mode (solid), and the coupled mode without CRF (dashed).

lies is not as regular as that of precipitation anomalies: between $10^{\circ}$ and $20^{\circ} \mathrm{N}$ the SST behavior can nearly be described as a standing oscillation, similar behavior to that found in observational studies (Vecchi and Harrison 2002; Duvel and Vialard 2007). The resulting SSTprecipitation phase lag is not constant, with the SST and precipitation anomalies being in phase around $10^{\circ} \mathrm{N}$. Except at the equator, the mixed layer depth amplitude, $\mathcal{A}_{H_{O}}$, is similar to the SST amplitude, $\mathcal{A}_{\mathcal{T}_{S}}$, with one maximum of amplitude in each hemisphere. The northern amplitude maximum $(25 \mathrm{~m})$ is consistent with the few available observations and evaluations in the $\mathrm{BoB}$ (Bhat et al. 2001; Moshonkin and Harenduprakash 1991), and the ratio between MLD and SST amplitudes is similar to simulations by ocean general circulation models (Waliser et al. 2004); $\mathcal{A}_{H_{O}}$ also exhibits secondary, synoptic-scale maxima around the equator that are unrelated to SST patterns. Interestingly, the SST and MLD anomalies are almost in phase opposition around their maxima: the OML thins during monsoon breaks and deepens during active phases in the BoB and in the Southern Hemisphere.
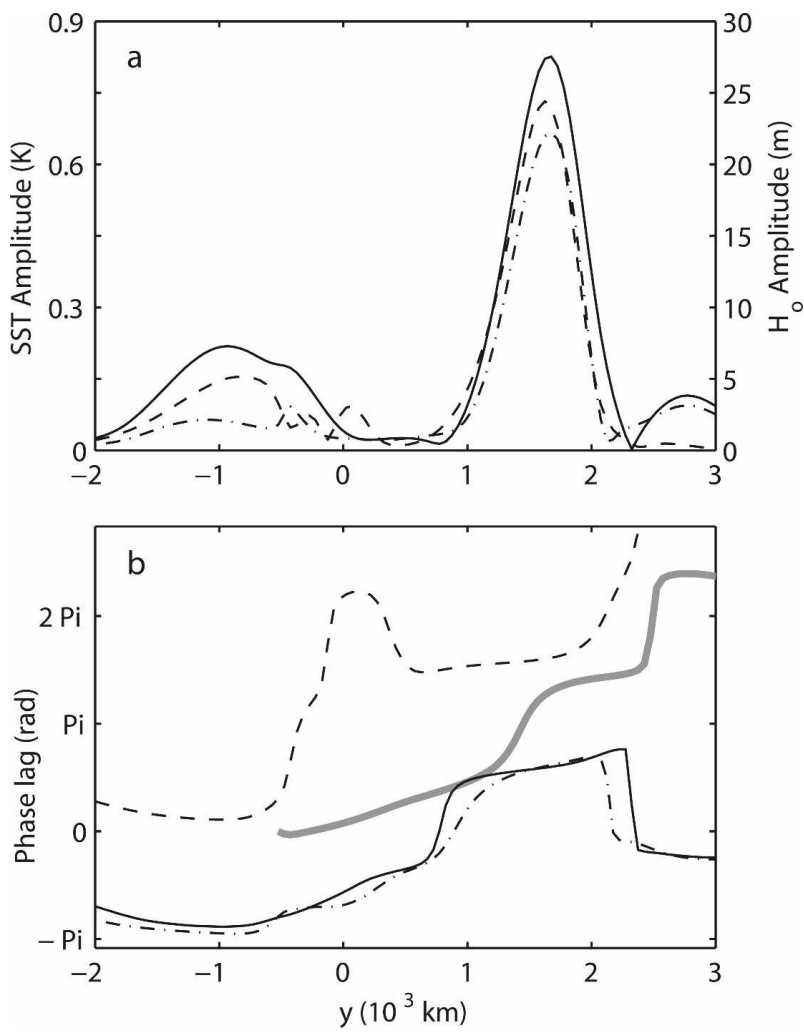

FIG. 5. (a) Amplitude and (b) phase of the SST (solid) and MLD (dashed) in the coupled mode, and SST (dash-dotted) in the coupled mode without ocean dynamics; the precipitation phase is also displayed (gray, thick line).

\section{b. Impact of the coupling on the atmospheric oscillation}

Ocean-atmosphere coupling shortens the period of the unstable mode significantly without changing either the structure of the atmospheric oscillation or the growth rate significantly. This result is consistent with some GCM results that have shown an improvement in the phase speed of the monsoon intraseasonal oscillation in coupled GCMs compared to the atmospheric GCMs alone (Kemball-Cook et al. 2002; Zheng et al. 2004). We examine the net surface flux to understand how the SST anomalies feed back on the atmosphere in our model. This flux has a radiative and a turbulent contribution, and the latter can further be decomposed into a component associated with SST perturbations, a component due to ABL thermodynamic perturbations $\left(s_{b}^{\prime}\right.$ and $q_{b}^{\prime}$ ) and a wind-induced effect [see Eqs. (6) and (7)]. Figure 6 shows the amplitudes and phases of these different contributions. Except between the equator and $10^{\circ} \mathrm{N}$ where the radiative flux is dominant (and the total surface flux and SST amplitudes are very small), the net surface flux is dominated by the wind-induced 

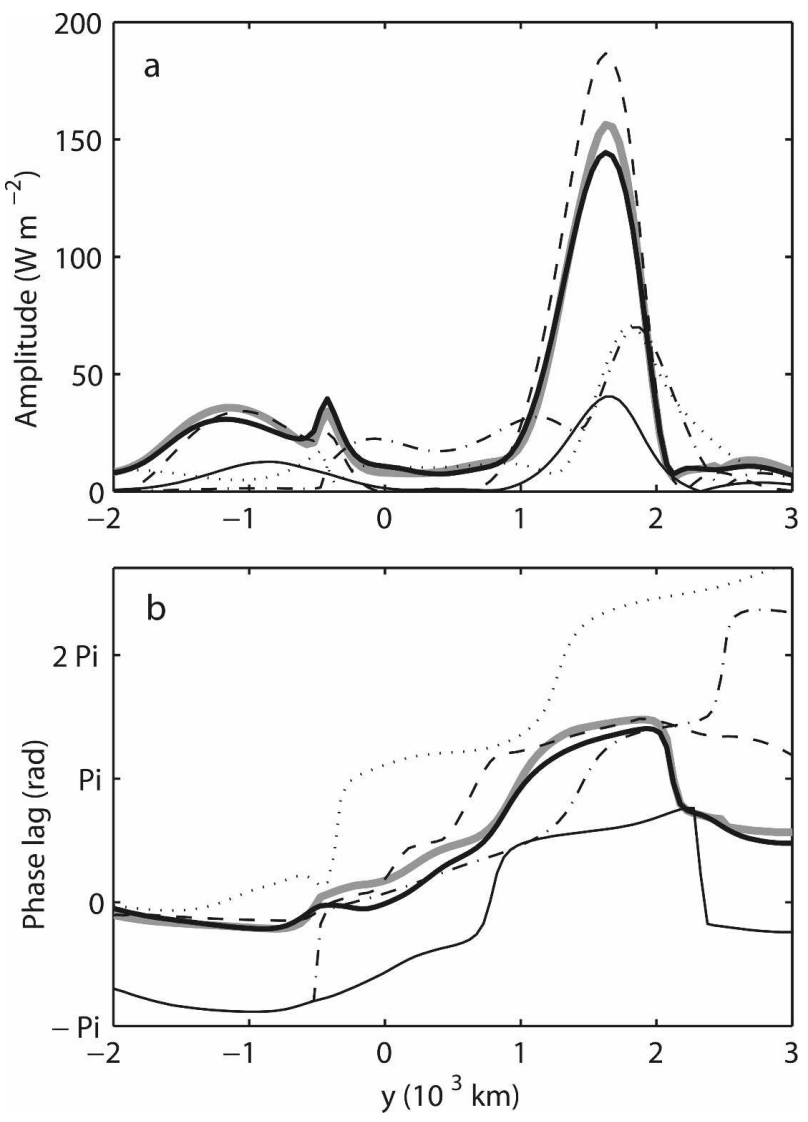

FIG. 6. (a) Amplitude and (b) phase of the upward net surface heat flux (thick, black line) and its SST (solid), ABL (dotted), wind-induced (dashed), and radiative (dash-dotted) contributions in the coupled mode; the amplitude and phase of the upward net surface heat flux in the uncoupled mode are also indicated (thick, gray line).

turbulent fluxes. The flux related to SST perturbations is about 5 times smaller than the wind-induced contribution, and its structure is similar. Furthermore, the phase lag between wind- and SST-induced contributions is almost independent of latitude, between quadrature and phase opposition. As a result, the structure of the net surface heat flux is modulated by oceanatmosphere interaction. Its amplitude is slightly smaller in the coupled mode than in the uncoupled mode, and the phase is shifted so that the surface flux lag relative to the precipitation is slightly smaller in the coupled mode than it is in the uncoupled mode.

In the uncoupled mode, surface fluxes slow the northward propagation (see BSb), because the maximum of surface fluxes is located south of the precipitation maximum. This is due to the wind-induced effect associated with the cyclonic circulation around the convection maximum, combined with the mean westerly surface flow. By reducing the surface fluxes and shifting their patterns northward, the SST anomalies diminish their slowing effect and therefore accelerate the propagation. In other words, a positive SST anomaly, because it results from the monsoon break ahead of the precipitation maximum associated with the current active phase, is located north of that precipitation maximum (as shown in Fig. 3). This positive SST anomaly thus enhances evaporation north of the precipitation maximum, favoring the northward propagation of the precipitation relative to what would occur in the absence of the SST anomaly. The ocean-atmosphere coupling does not cause a significant latitudinal reorganization of the atmospheric oscillation, because the latitudinal dependence of the amplitude and phase of the SSTinduced surface flux is similar to that of the surface flux contribution due to the anomalies of the atmospheric variables, which is in turn similar to the uncoupled case. The main effect of ocean-atmosphere coupling is therefore a phase shift of the net surface flux.

In $\mathrm{BSa}$ and $\mathrm{BSb}$, the variability of wind-induced surface fluxes was shown to be crucial to the instability of the intraseasonal mode by providing energy close to the maximum of atmospheric temperature, slightly south of the maximum of convection. The $e$-folding time of the coupled mode is similar to that of the uncoupled mode (see Table 2). The effect of the phase shift of the surface heat fluxes on the instability is compensated by the minor change in the amplitude of these fluxes.

\section{c. Processes of the ocean response}

To understand the oceanic response to the atmospheric oscillation, we study the budgets of energy and mass of the OML. Figure 7 displays the individual terms in the energy budget [see Eq. (1)]. The combination of entrainment of subsurface waters and surface fluxes dominates this budget. The horizontal transport (including advection and diffusion) and the solar flux at the bottom of the OML are much smaller. We performed an additional experiment neglecting $Q_{H_{O}}^{\prime}$ to investigate further the role of the solar flux at the bottom of the OML. The unstable eigenmode and eigenvalue in this case were almost identical to those in the control case (not shown), confirming the insignificance of penetrative solar radiation to the coupled mode's dynamics. The vertical transport and surface fluxes present some strong similarities: they both exhibit amplitude maxima in each hemisphere, located around $10^{\circ} \mathrm{S}$ and $15^{\circ} \mathrm{N}$, and they are almost in phase for most of the propagation. They therefore interact constructively to determine the time evolution of the SST, resulting in the amplitude maxima in Fig. 5: cooling is due to large net surface flux out of the ocean and simultaneous large entrainment of subsurface waters. 

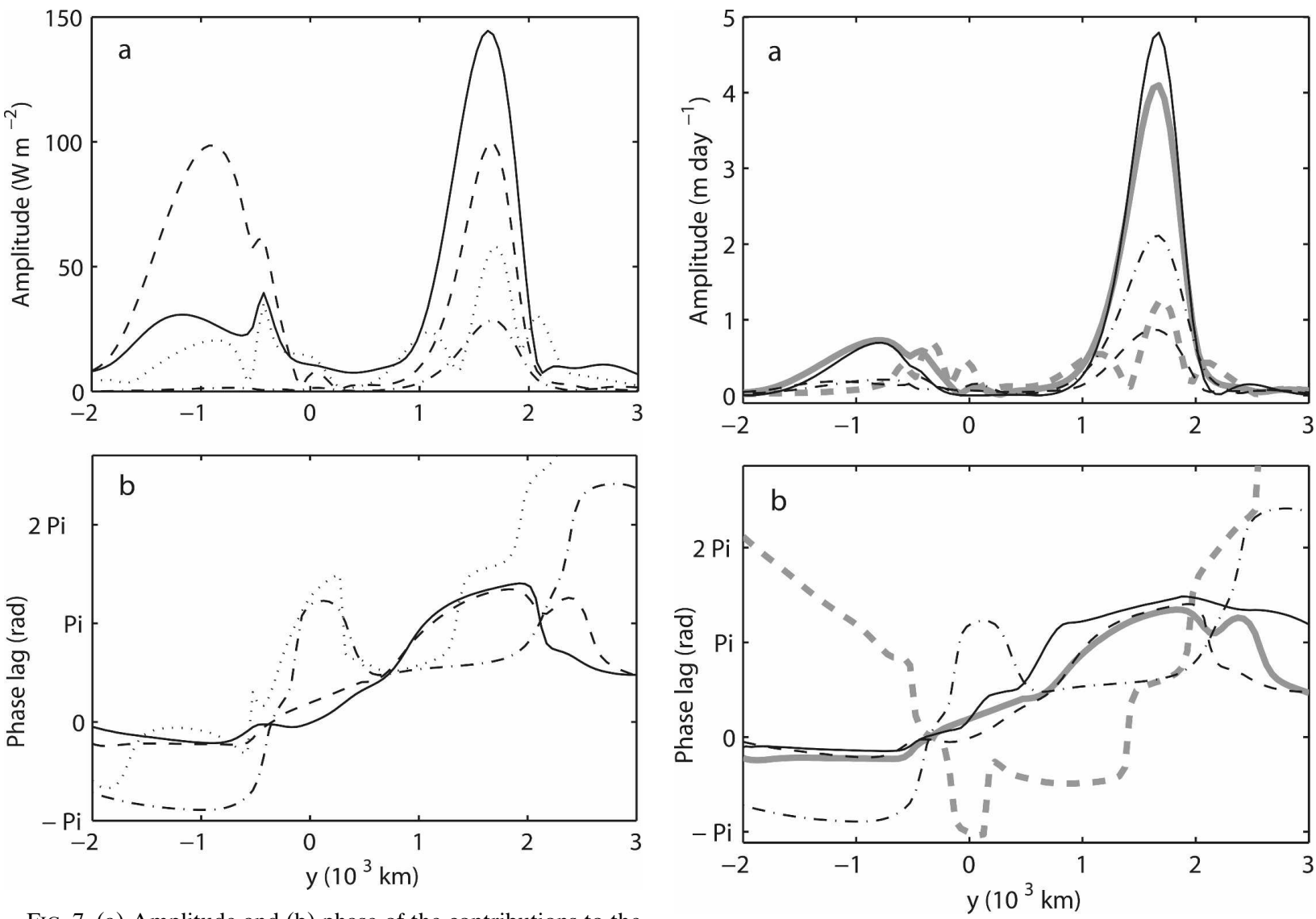

FIG. 7. (a) Amplitude and (b) phase of the contributions to the OML energy budget: net surface flux (solid), bottom flux (dashdotted), horizontal transport (dotted), and vertical transport (dashed).

The surface flux and vertical transport terms differ somewhat in their latitudinal structure. The vertical transport has two maxima of similar amplitude, one in each hemisphere, while the surface flux has a large maximum (somewhat larger than that of the vertical transport, though of the same order) in the Northern Hemisphere, and a much smaller one in the Southern.

Figure 8 shows the different terms of the OML mass budget [see Eq. (3)]. The horizontal transport (including diffusion) has little influence on the thinning and deepening of the OML, the latter being controlled by entrainment of subsurface waters: large entrainment of subsurface waters is associated with increases in MLD.

These results lead to the following explanation of the relationship between the variability in SST and MLD. The entrainment and net surface heat flux have similar structure and timing. Positive entrainment anomalies cause a deepening and cooling of the OML, and the simultaneous net surface flux of the same sign enhances the cooling. The time evolution of the MLD and SST therefore have similar patterns and opposite signs. This

FIG. 8. (a) Amplitude and (b) phase of the contributions to the OML mass budget: horizontal dynamics (thick, gray, dashed) and entrainment (thick, gray, solid); the latter is further decomposed in the contributions of wind stirring (solid), surface buoyancy flux (dashed), and MLD changes (dash-dotted).

results in the phase opposition between SST and MLD, and their similar patterns (see Fig. 5). This aspect of our model intraseasonal mode is similar to observed and modeled properties of the MJO in which the SST perturbations are controlled by the combination of surface fluxes and upwelling (Shinoda and Hendon 1998, 2001).

We now study the various dynamically distinct contributions to both the net surface flux and entrainment in order to understand why they have similar variability. We noted above that the surface net flux is dominated by the wind-induced effect (see Fig. 6); this effect is proportional to the scalar product $\overline{\mathbf{v}}_{b} \cdot \mathbf{v}_{b}^{\prime}$. On the other hand, Fig. 8 shows the different contributions to the entrainment [i.e., the different terms in Eq. (16)]. It appears that the amplitude and phase of entrainment are dominated by the effect of the wind stirring, which is also proportional to the scalar product $\overline{\mathbf{v}}_{b} \cdot \mathbf{v}_{b}^{\prime}$. The damping contribution of the MLD anomalies is much smaller; it mainly takes into account the small effect of the changes in solar input through the entrainment clo- 
sure. The surface buoyancy flux anomalies are proportional to the net surface heat flux anomalies, and, though small, they reinforce the similarity between entrainment and net surface heat flux. Therefore the patterns of both net surface flux and entrainment follow the pattern of $\overline{\mathbf{v}}_{b} \cdot \mathbf{v}_{b}^{\prime}$, which explains their similarity, and the phase lag between the similar patterns of $T_{s}^{\prime}$ and $H_{o}^{\prime}$.

To understand the respective roles of the oceanic transport and thermodynamic response, we perform an additional experiment in which the ocean dynamics are neglected and the ocean is modeled by a "slab" layer of steady, latitude-dependent depth $\bar{H}_{o}(y)$. The unstable mode of this slab model has a period of 54.5 days $(20 \%$ shorter than the uncoupled mode) and an $e$-folding time of 15.4 days. Table 2 shows that the thermodynamic response of the OML is responsible for most of the decrease in period from the uncoupled to the coupled mode. The instability is almost the same as in the uncoupled model. Figure 5 shows the SST response in this slab model. The SST follows the same pattern as in the complete model, but with a much smaller maximum in the Southern Hemisphere. It appears that the thermodynamic response alone accounts for up to $80 \%$ of the SST anomalies (of the complete model) in the northern tropics but only to a third of the SST anomalies in the Southern Hemisphere. This results from the strong impact of entrainment there, which in turn results from the availability of cold subsurface waters compared to the warm subsurface waters in the BoB [see Eqs. (18) and (19)].

\section{d. Role of cloud forcing}

We investigate the sensitivity of the model to the CRF. We perform an experiment in which the CRF is set to zero $(r=0)$. In this configuration, the model still has one unstable mode with a period of 48 days and an $e$-folding time of 71.9 days (see Table 2). As shown in somewhat simpler models, CRF reduces the effective gross moist stability of baroclinic circulations (Bretherton and Sobel 2002; Sobel et al. 2004; Neelin et al. 2003; Chou and Neelin 2004; Raymond 2000), which tends to further destabilize the model atmosphere to whatever transients it is already unstable or render marginally stable modes unstable. It also slightly slows the northward propagation, a response that is similar to the model's sensitivity to a shorter convective time scale (see $\mathrm{BSb})$.

The structure of the atmospheric oscillation is similar to that in the control case, except for a larger precipitation amplitude at the equator (see Fig. 4). Note that the impact of the CRF on the structure of the atmospheric oscillation is nevertheless larger than the impact
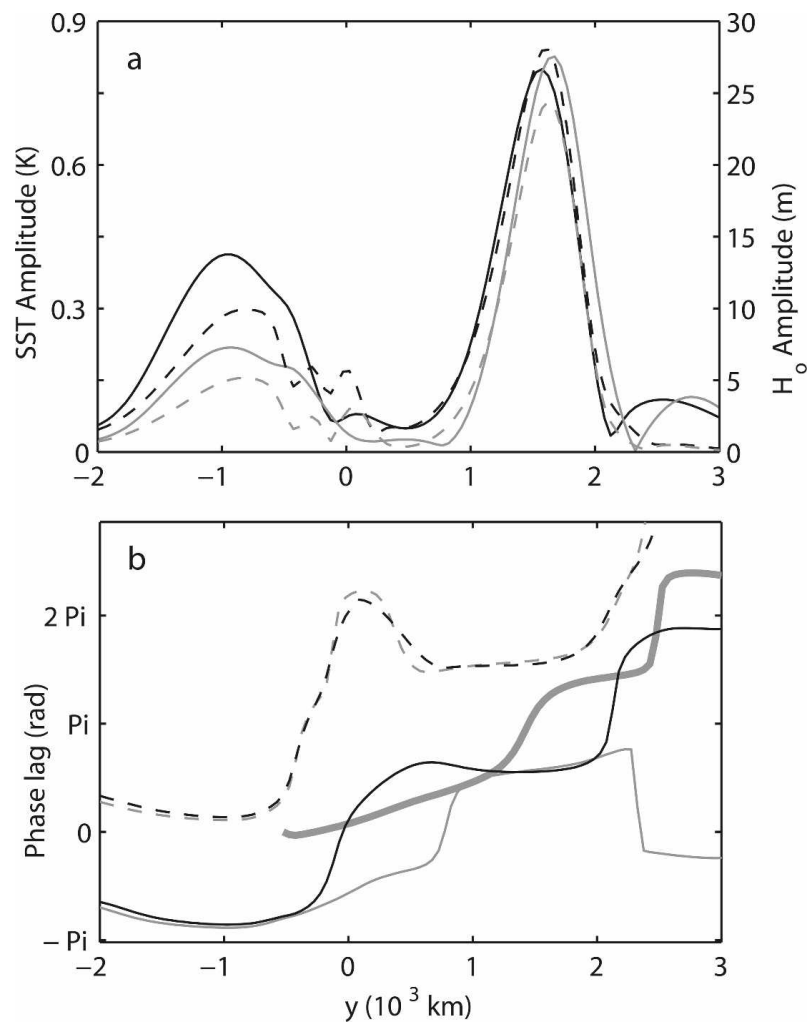

FIG. 9. (a) Amplitude and (b) phase of the SST (black, solid) and MLD (black, dashed) in the coupled mode without CRF, and their counterparts in the control case (gray); the precipitation phase is also displayed (gray, thick line).

of the ocean-atmosphere coupling. This highlights the fact that this intraseasonal mode is largely an atmospheric phenomenon with a small modulation by the ocean. Figure 9 displays the structures of SST and MLD anomalies. The amplitudes of both SST and MLD have similar patterns as in the control case except that both amplitudes south of $10^{\circ} \mathrm{N}$ are about twice larger in the no-CRF case compared to the control case. This results from the larger stirring and wind-induced surface heat flux associated with the circulation caused by the larger precipitation amplitude at the equator. While the MLD phase is not modified significantly by the CRF, the SST does not propagate northward in the no-CRF case. Instead, it undergoes a standing oscillation with a phase opposition between the Northern and Southern Hemispheres, with a change in sign of the phase lag between SST and precipitation.

In the absence of CRF, the anomaly of the surface radiative flux perturbation is very small $\left(\epsilon_{T} T_{s}^{\prime}\right)$, and the net surface flux is dominated by the wind-induced contribution everywhere. This contribution is controlled on a basinwide scale by the response of the dynamics to convection anomalies. In our model, the Northern 
Hemisphere atmospheric circulation responds mostly to the strong variability of convection around $20^{\circ} \mathrm{N}$. This promotes a basinwide control of the surface flux, entrainment, and, therefore, SST by the precipitation in the monsoon TCZ. This in turn results in a standing oscillation of SST with a changing SST-precipitation phase lag. When cloud effects are included, the CRF promotes a local control of the SST by convection and, therefore, a phase lag between precipitation and SST that is more similar from one latitude to the next. Observations tend to support the existence of both the local and nonlocal effects. While some composites show regular northward propagation of the SST (Wang et al. 2006; Roxy and Tanimoto 2007), some other studies point out the standing and basinwide character of the SST signal (Vecchi and Harrison 2002; Duvel and Vialard 2007).

\section{Sensitivity to the basic-state MLD}

We explore the sensitivity of our model results to the basic structure of the ocean. First, we set the basic-state MLD, $\bar{H}_{o}$, independent of latitude and vary its value as a control parameter. Figure 10 shows the period and growth rate of the unstable eigenmode as a function of $\bar{H}_{o}$. Our control experiment with latitude-dependent $\bar{H}_{o}$ has characteristic time scales similar to those in the case with a uniform $\bar{H}_{o} \approx 35 \mathrm{~m}$, which is the average MLD in the BoB. Second, we perform the same series of experiments with a slab layer (see dash-dotted line in Fig. 10).

The basic state becomes stable when $\bar{H}_{o}<10 \mathrm{~m}$ in both the complete model and the slab model. This can be explained by the changes in the patterns of surface heat fluxes when the MLD is small. For an infinitely thin slab layer, there cannot be any heat storage in the oceanic layer and the energy budget imposes that the SST adjusts instantaneously to maintain a zero net flux at the surface. We pointed out in section $3 b$ that the surface flux variability is crucial to the instability of the mode; shutting down this variability stabilizes the basic state. The behavior of the complete OML model is more complex because of entrainment; for a very small $\bar{H}_{o}$, Eqs. (1), (3), and (16) can be rewritten at zeroth order in $\bar{H}_{o}$ as

$$
\begin{aligned}
w_{e}^{\prime} \rho_{w r} C_{w} \delta T_{o}+E^{\prime}+H^{\prime} & =0, \\
\partial_{t} H_{o}^{\prime} & =w_{e}^{\prime}, \\
m_{s}^{\prime} \bar{V}_{s} \overline{\mathbf{v}}_{b} \cdot \mathbf{v}_{b}^{\prime}-J_{0} H_{o}^{\prime} & =0,
\end{aligned}
$$

where we also neglected the radiative contribution to the OML energy budget. We can therefore write the zeroth order surface heat flux as follows:
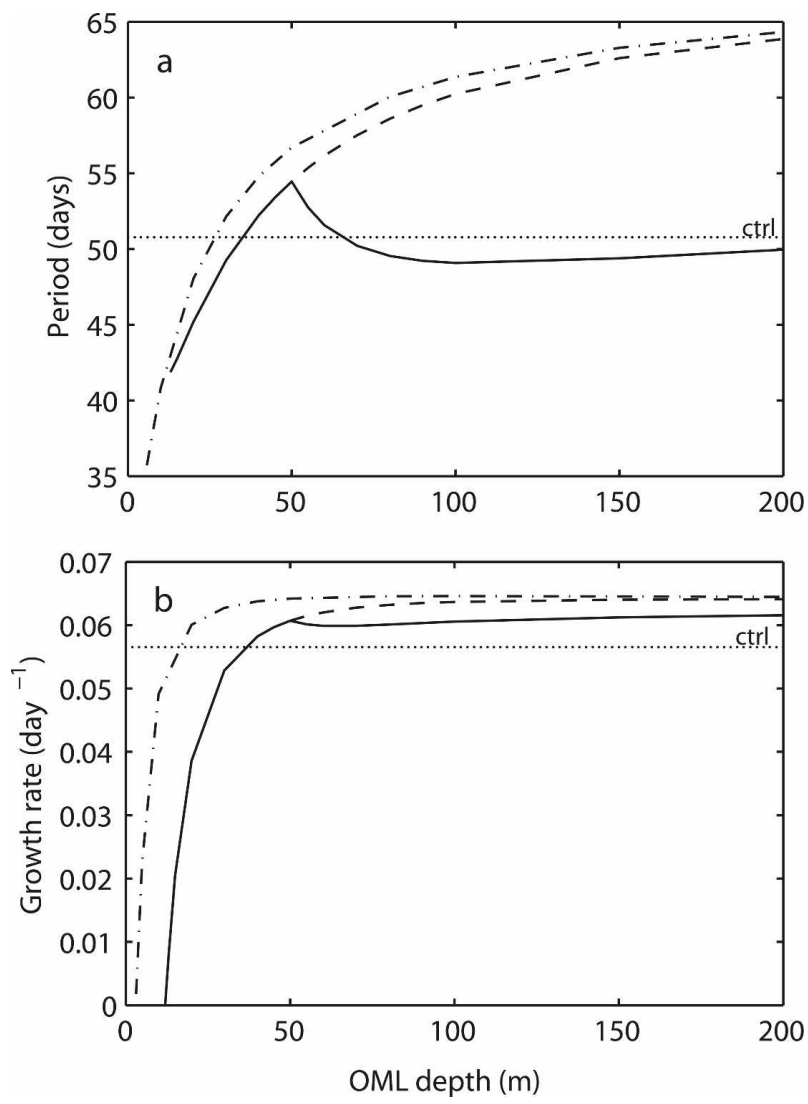

FIG. 10. (a) Period $\mathcal{T}$ and (b) growth rate $\Gamma$ of the unstable mode as a function of the uniform base-state MLD $\bar{H}_{o}$ with the control seasonal stratification (solid), with a uniform temperature jump $\overline{\Delta T}_{o}=0.5 \mathrm{~K}$ at the bottom of the OML (dashed), and without dynamics (dash-dotted); the period and growth rate of the control case are also shown (dotted).

$$
E^{\prime}+H^{\prime}=-\frac{m_{s}^{\prime} \overline{\mathrm{V}}_{s} \delta T_{o}}{\alpha g \Sigma \bar{S}_{o}} \overline{\mathbf{v}}_{b} \cdot \partial_{t} \mathbf{v}_{b}^{\prime}
$$

Hence, for a small $\bar{H}_{o}$, the SST adjusts so that the surface heat flux patterns are driven by $-\overline{\mathbf{v}}_{b} \cdot \partial_{t} \mathbf{v}_{b}^{\prime}$, in phase quadrature with their patterns in the control case that are controlled by $\overline{\mathbf{v}}_{b} \cdot \mathbf{v}_{b}^{\prime}$. Instead of convection lagging a surface flux minimum and leading a surface flux maximum as in the control case, for small $\bar{H}_{o}$ the convection maximum is almost collocated with a minimum of surface fluxes. This damps the unstable mode, even more efficiently than in the case of a slab layer.

It is reasonable to assume that the growth rate, as a measure of the instability of the base state, can be considered as a proxy for the amplitude of the corresponding nonlinear oscillation. This stabilization of the coupled mode for small $\bar{H}_{o}$ is therefore similar to the GCM results of Maloney and Sobel (2004), where the southern MJO was damped for thin oceanic mixed lay- 
ers. This may be related to the continent-ocean contrasts in intraseasonal variability. Observations show relative minima of intraseasonal activity over the continents. During northern summer, at similar latitudes, intraseasonal variability over India, Indochina, China, and Indonesia is weaker than over the adjacent seas (Duvel and Vialard 2007). During southern summer, the MJO-related variability is minimum over the Maritime Continent (Duvel and Vialard 2007). Maloney and Sobel (2004) suggested that this minimum of MJO activity is due to the small thermal inertia of land. Our model results suggest this could also be the case in the Asian monsoon intraseasonal oscillation. This highlights that some characteristics are common to the MJO and the Asian monsoon intraseasonal oscillation.

With the ocean stratification used in the control case, both the period and growth rate have weak maxima for $\bar{H}_{o}=H_{c}=50 \mathrm{~m} ; \overline{\Delta T}_{o}$ is a strongly nonlinear function of $H_{o}$ at $H_{c}$. If we change $H_{c}$, the period and growth rate maxima follow $H_{c}$, except that the growth-rate maximum disappears for small values of $H_{c}$. If we remove this nonlinearity (which in any case is in the parameter variations from one experiment to the next only; the model itself remains linear in all cases) by setting $\overline{\Delta T}_{o}$ to $0.5 \mathrm{~K}$ everywhere, the maxima of $\Gamma$ and $\mathcal{T}$ disappear. In this case, the growth rate and period increase monotonically with $\bar{H}_{o}$ and tend toward their uncoupled values for $\bar{H}_{o} \rightarrow \infty$ (see Fig. 10). The same sensitivity experiment without ocean dynamics gives a similar result except that the growth rate has a maximum very slightly larger than the uncoupled value for $\bar{H}_{o}$ close to $100 \mathrm{~m}$ (see dash-dotted line in Fig. 10).

This result is reminiscent of the weak maximum of precipitation variability obtained in Maloney and Sobel (2004), except that the maximum here is weaker still than the one obtained in that study and occurs at a much deeper MLD (100 m versus $20 \mathrm{~m}$ ). In this respect, there is one other difference between the present results and those of Maloney and Sobel (2004). Maloney and Sobel (2004) compared GCM results to the simple single-column model of Sobel and Gildor (2003), which also has an amplitude maximum at an MLD of 10-20 m when the model is run in a stable regime and externally forced. In that model, the maximum becomes stronger for larger cloud-radiative feedback parameter $r$, becoming fairly sharp (large enhancement in amplitude over the uncoupled case) as $r$ approaches the value that renders the model unstable to free oscillations. In the present model, on the contrary, increasing the cloud -radiative feedback parameter $r$ does not enhance the very weak growth rate maximum but, in fact, renders it even weaker still (not shown). This difference in the sensitivity of the two models could result from a num- ber of factors, including differences in the models themselves and the experiment designs as well as, possibly, differences in the dynamical nature of the modes themselves-northward propagating here, eastward propagating MJO in Maloney and Sobel (2004), single column (and externally forced) in Sobel and Gildor (2003). We do not currently understand which of these factors is responsible for the difference in the structure of the growth rate or amplitude curves as a function of MLD, or the variations of this structure with $r$. In the observations, Bellenger and Duvel (2007) found some evidence of increased atmospheric variability over moderately thin (20-30 m deep) OML compared to deeper mixed layers during both summer and winter.

On the other hand, the increase of phase speed with decreasing $\bar{H}_{o}$ appears as a robust result for the MJO (Watterson 2002; Maloney and Sobel 2004), and our results suggest that it is also valid for the monsoon intraseasonal oscillation.

\section{Summary and discussion}

We have used an idealized model-the linear QTCM2 in an aquaplanet, axisymmetric, $\beta$-plane configuration, coupled to a simple model of the upper ocean-to study the effect of ocean-atmosphere coupling on the monsoon intraseasonal oscillation. We investigated the respective roles of cloud radiative forcing and ocean dynamics. Our main results are the following:

1) Our model SST intraseasonal pattern is similar to the observed variability of SST in the BoB and the west Pacific with a maximum of variability between $10^{\circ}$ and $20^{\circ} \mathrm{N}$ (Duvel and Vialard 2007). When the precipitation amplitude is scaled to match the observations, the SST amplitude maximum is about 0.8 $\mathrm{K}$, similar to observed values (Vecchi and Harrison 2002). The SST anomalies propagate northward, and the simulated phase relationship between SST and precipitation is similar to observations (Vecchi and Harrison 2002; Duvel and Vialard 2007) for most of the propagation. The SST precedes the precipitation, by up to a quarter of period (about 13 days in our model) in the north of the BoB: the ocean surface warms during monsoon breaks and cools during active phases. Entrainment of subsurface waters and net surface flux have similar patterns, almost in phase. This suggests that a SST reconstruction considering the effect of the observed net surface flux on a slab ocean (Sengupta et al. 2001) will misleadingly succeed if the effect of entrainment is compensated by an adequate choice of MLD. 
2) The MLD anomalies exhibit the same pattern as the SST anomalies, with opposite sign: the BoB OML thins during monsoon breaks and thickens during active phases. This phase opposition between SST and MLD is explained by the control of windinduced effects over both. Wind stirring dominates entrainment, and wind-induced sensible and latent heat fluxes dominate the net surface flux.

3) The turbulent surface heat flux, dominated by its wind-induced component, tends to establish a standing SST oscillation via the variability of basinwide circulation that is nonlocally controlled by convection in the monsoon trough at $20^{\circ} \mathrm{N}$. On the other hand, the shortwave cloud radiative forcing promotes a local control of the SST by convection and tends to establish a northward propagation of the SST in quadrature with the precipitation.

4) The ocean-atmosphere coupling shortens the period by $25 \%$ in our model; that is, the northward phase speed is increased. The thermodynamic response of the OML is responsible for a $20 \%$ decrease in period and the oceanic dynamical response explains the remaining difference. In this matter, GCM experiments yield nonconclusive results: some experiments exhibit an increase of the phase speed with the coupling (Kemball-Cook et al. 2002; Zheng et al. 2004) while others display the opposite behavior ( Fu and Wang 2004a), and these results appear sensitive to the nature (seasonal or daily) of the SST forcing imposed on the atmospheric GCM (Fu and Wang 2004b). Otherwise, the structure of the atmospheric mode, as described by the amplitude and phase of the precipitation, is not modified significantly by the ocean-atmosphere coupling.

5) We investigated the sensitivity of our model to changes in the seasonal MLD. The basic state becomes stable when the base-state MLD is decreased below $10 \mathrm{~m}$. This suggests that the observed reduction of intraseasonal variability over India and Indochina might be associated to the weak thermal inertia of land.

Though the relevance of our linear atmospheric model has been demonstrated (BSa), the use of a linear OML model can only be a first step in understanding the ocean-atmosphere coupling (especially considering that the MLD perturbations are of the same order of magnitude as the base-state MLD). Nonlinear oceanic processes may play an important role in the modulation of the MLD and of the thermal inertia of the OML, and ought to be investigated.

Our results also raise questions about the coupling with continental surfaces. Originally thought to be cru- cial for the intraseasonal variability (Webster 1983), land-atmosphere interactions are now suspected to damp the intraseasonal activity. Our results show that the weak thermal inertia of land could be responsible for this damping, but it could also involve other, mostly nonlinear, factors such as the availability of humidity. We hope to address these questions in future work.

One limitation of this study is the use of a zonally symmetric domain. While use of a zonally symmetric atmospheric model in studying monsoon intraseasonal oscillation (e.g., Goswami and Shukla 1984; Jiang et al. 2004) is justified owing to the long zonal scale of the intraseasonal oscillation and lack of any boundaries in the atmosphere, the use of a zonally symmetric ocean may not be equally justified. We do, however, feel that both observational studies and theoretical arguments suggest that the zonally symmetric ocean used in this study is a good first-order approximation. From a theoretical point of view, the zonally symmetric framework will exclude oceanic Rossby waves, wind-driven coastal upwelling, and coastal currents associated with coastal Kelvin wave propagation. It is unlikely that Rossby wave dynamics will play a role at intraseasonal time scale since the fastest Rossby waves would take about 80 days at $10^{\circ} \mathrm{N}$ and more than 160 days north of $15^{\circ} \mathrm{N}$ to cross the BoB (Killworth et al. 1997) - a long time compared to monsoon intraseasonal oscillation. There is, however, a recent study (Durand et al. 2008, manuscript submitted to J. Geophys. Res.) suggesting a significant modulation of the coastal currents around India, probably partly in response to intraseasonal variability. However, observations of the SST intraseasonal variability in the BoB show a rather zonal structure with maximum variance in the northern bay (see Fig. 2 of Vecchi and Harrison 2002; Fig. 3 of Sengupta et al. 2001; Fig. 7h of Duvel and Vialard 2007). This suggests that coastal Kelvin waves and coastal upwelling do not drive any particular SST variability close to the eastern and western boundaries in the Bay of Bengal. It cannot be excluded, though, that part of the increase of the SST variability toward the north could be due to increased coastal upwelling during active monsoon phases. We thus feel that the zonally symmetric configuration is probably a good framework for this study, but that the addition of a coastal boundary to the north of the domain is an interesting perspective.

Acknowledgments. We acknowledge interesting discussions with G. Vecchi and E. Maloney. We would also like to thank Pr. D. Sengupta for useful comments, and K. Strounine. This work was supported in part by NSF Grant ATM-05-42736. 


\section{REFERENCES}

Bellenger, H., and J.-P. Duvel, 2007: Intraseasonal convective perturbations related to the seasonal march of the Indo-Pacific monsoons. J. Climate, 20, 2853-2863.

Bellon, G., and A. H. Sobel, 2008a: Poleward-propagating intraseasonal monsoon disturbances in an intermediatecomplexity axisymmetric model. J. Atmos. Sci., 65, 470-489.

$\longrightarrow$, and — 2008b: Instability of the axisymmetric monsoon flow and intraseasonal oscillation. J. Geophys. Res., 113, D07108, doi:10.1029/2007JD009291.

Bhat, G. S., and Coauthors, 2001: BOBMEX: The Bay of Bengal Monsoon Experiment. Bull. Amer. Meteor. Soc., 82, 22172243.

Bretherton, C. S., and A. H. Sobel, 2002: A simple model of a convectively coupled walker circulation using the weak temperature gradient approximation. J. Climate, 15, 2907-2919.

Chatterjee, P., and B. N. Goswami, 2004: Structure, genesis and scale selection of the tropical quasi-biweekly mode. Quart. J. Roy. Meteor. Soc., 130, 1171-1194.

Chou, C., and J. D. Neelin, 2004: Mechanisms of global warming impacts on regional tropical precipitation. J. Climate, 17, 2688-2701.

Dai, A. G., 2006: Precipitation characteristics in eighteen coupled climate models. J. Climate, 19, 4605-4630.

de Boyer Montégut, C., G. Madec, A. S. Fischer, A. Lazar, and D. Iudicone, 2004: Mixed layer depth over the global ocean: An examination of profile data and a profile-based climatology. J. Geophys. Res., 109, C12003, doi:10.1029/2004JC002378.

Drbohlav, H.-K., and B. Wang, 2005: Mechanism of the northward-propagating intraseasonal oscillation: Insights from a zonally symmetric model. J. Climate, 18, 952-972.

Duvel, J.-P., and J. Vialard, 2007: Indo-Pacific sea surface temperature perturbations associated with intraseasonal oscillations of tropical convection. J. Climate, 20, 3056-3082.

_, R. Roca, and J. Vialard, 2004: Ocean mixed layer temperature variations induced by intraseasonal convective perturbations over the Indian Ocean. J. Atmos. Sci., 61, 1004-1023.

Flatau, M., P. J. Flatau, P. Phoebus, and P. P. Niller, 1997: The feedback between equatorial convection and local radiative and evaporative processes: The implications for intraseasonal oscillations. J. Atmos. Sci., 54, 2373-2386.

Fu, X., and B. Wang, 2004a: The boreal-summer intraseasonal oscillations simulated in a hybrid coupled atmosphere-ocean model. Mon. Wea. Rev., 132, 2628-2649.

— sonal oscillations simulated in an atmosphere-ocean coupled model and an atmosphere-only model. J. Climate, 17, 12631271.

$\longrightarrow,-$, D. E. Waliser, and L. Tao, 2007: Impact of atmosphere-ocean coupling on the predictability of monsoon intraseasonal oscillations. J. Atmos. Sci., 64, 157-174.

Goswami, B. N., 2005: South Asian monsoon. Intraseasonal Variability in the Atmosphere-Ocean Climate System, W. K. M. Lau and D. E. Waliser, Eds., Springer, 19-61.

— metric general circulation model. J. Atmos. Sci., 41, 20-37.

Hendon, H. H., 2000: Impact of air-sea coupling on the MaddenJulian oscillation in a general circulation model. J. Atmos. Sci., 57, 3939-3952.

Inness, P. M., and J. M. Slingo, 2003: Simulation of the MaddenJulian oscillation in a coupled general circulation model. Part
I: Comparison with observations and an atmosphere-only GCM. J. Climate, 16, 345-364.

Jiang, X., T. Li, and B. Wang, 2004: Structures and mechanisms of the northward propagating boreal summer intraseasonal oscillation. J. Climate, 17, 1022-1039.

Kang, I. S., and Coauthors, 2002: Intercomparison of the climatological variations of Asian summer monsoon precipitation simulated by 10 GCMs. Climate Dyn., 19, 383-395.

Kemball-Cook, S., B. Wang, and X. H. Fu, 2002: Simulation of the intraseasonal oscillation in the ECHAM-4 model: The impact of coupling with an ocean model. J. Atmos. Sci., 59, 14331453.

Killworth, P. D., D. B. Chelton, and R. A. de Szoeke, 1997: The speed of observed and theoretical long extratropical planetary waves. J. Phys. Oceanogr., 27, 1946-1966.

Lawrence, D. M., and P. Webster, 2002: The boreal summer intraseasonal oscillation: Relationship between northward and eastward movement of convection. J. Atmos. Sci., 59, 15931606.

Lin, J., and B. E. Mapes, 2004: Radiation budget of the tropical intraseasonal oscillations. J. Atmos. Sci., 61, 2050-2062.

Maloney, E., and A. H. Sobel, 2004: Surface fluxes and ocean coupling in the tropical intraseasonal oscillation. J. Climate, 17, 4368-4386.

Moshonkin, S. M., and L. Harenduprakash, 1991: Effect of salinity and transparency on the mixed layer thermal structure in the Bay of Bengal. Oceanology, 31, 276.

Neelin, J. D., and N. Zeng, 2000: A quasi-equilibrium tropical circulation model-Formulation. J. Atmos. Sci., 57, 17411766.

- C. Chou, and H. Su, 2003: Tropical drought regions in global warming and El Niño teleconnections. Geophys. Res. Lett., 30, 2275, doi:10.1029/2003GL018625.

Niiler, P. P., and E. B. Kraus, 1977: One-dimensional models of the upper ocean. Modeling and Prediction of the Upper Layers of the Ocean, E. B. Kraus, Ed., Pergamon Press, 143-172.

Rajendran, K., and A. Kitoh, 2006: Modulation of tropical intraseasonal oscillations by ocean-atmosphere coupling. $J$. Climate, 19, 366-391.

$\longrightarrow, \ldots$, and O. Arakawa, 2004: Monsoon low-frequency intraseasonal oscillation and ocean-atmosphere coupling over the Indian Ocean. Geophys. Res. Lett., 31, L02210, doi:10.1029/2003GL019031.

Ramanathan, V., R. D. Cess, E. F. Harrison, P. Minnis, B. R. Barkstrom, E. Ahmad, and D. Hartmann, 1989: Cloudradiative forcing and climate: Results from the earth radiation budget experiment. Science, 243, 57-63.

Raymond, D. J., 2000: The Hadley circulation as a radiativeconvective instability. J. Atmos. Sci., 57, 1286-1297.

Roxy, M., and Y. Tanimoto, 2007: Role of SST over the Indian Ocean in influencing the intraseasonal variability of the Indian summer monsoon. J. Meteor. Soc. Japan, 85, 349-358.

Sengupta, D., B. N. Goswami, and R. Senan, 2001: Coherent intraseasonal oscillations of ocean and atmosphere during the Asian summer monsoon. Geophys. Res. Lett., 28, 4127-4130.

Shinoda, T., and H. H. Hendon, 1998: Mixed layer modeling of intraseasonal variability in the tropical western Pacific and Indian Oceans. J. Climate, 11, 2668-2685.

— Madden-Julian oscillation in the western equatorial Pacific. J. Climate, 14, 4147-4165.

$\_, \ldots$, and J. Glick, 1998: Intraseasonal variability of surface 
fluxes and sea surface temperature in the tropical western Pacific and Indian Oceans. J. Climate, 11, 1682-1702.

Sikka, D. R., and S. Gadgil, 1980: On the maximum cloud zone and the ITCZ over Indian longitude during southwest monsoon. Mon. Wea. Rev., 108, 1840-1853.

Sobel, A. H., and H. Gildor, 2003: A simple time-dependent model of SST hot spots. J. Climate, 16, 3978-3992.

_ , and J. D. Neelin, 2006: The boundary layer contribution to intertropical convergence zones in the quasi-equilibrium tropical circulation model framework. Theor. Comput. Fluid Dyn., 20, 323-350.

- C. S. Bretherton, H. Gildor, and M. E. Peters, 2004: Convection, cloud-radiative feedbacks and thermodynamic ocean coupling in simple models of the walker circulation. Earth's Climate: The Ocean-Atmosphere Interaction, Geophys. Monogr., Vol. 147, Amer. Geophys. Union, 393-405.

Vecchi, G. A., and D. E. Harrison, 2002: Monsoon break and subseasonal sea surface temperature variability in the Bay of Bengal. J. Climate, 15, 1485-1493.

Waliser, D. E., and Coauthors, 2003: AGCM simulations of intraseasonal variability associated with the Asian summer monsoon. Climate Dyn., 21, 423-446.

- R. Murtugudde, and L. E. Lucas, 2004: Indo-Pacific ocean response to atmospheric intraseasonal variability: 2 . Boreal summer and the intraseasonal oscillation. J. Geophys. Res., 109, C03030, doi:10.1029/2003JC002002.
Wang, B., P. J. Webster, K. Kikuchi, T. Yasunari, and Y. Qi, 2006: Boreal summer quasi-monthly oscillation in the global tropics. Climate Dyn., 27, 661-675.

Watterson, I. G., 2002: The sensitivity of subannual and intraseasonal tropical variability to model ocean mixed layer depth. $J$. Geophys. Res., 107, 4020, doi:10.1029/2001JD000671.

- and J. Syktus, 2007: The influence of air-sea interaction on the Madden-Julian oscillation: The role of the seasonal mean state. Climate Dyn., 28, 703-722.

Webster, P. J., 1983: Mechanism of monsoon low-frequency variability: Surface hydrological effects. J. Atmos. Sci., 40, 2110 2124.

Woolnough, S. J., J. M. Slingo, and B. J. Hoskins, 2000: The relationship between convection and sea surface temperature on intraseasonal timescales. J. Climate, 13, 2086-2104.

—, F. Vitart, and M. A. Balmaseda, 2007: The role of the ocean in the Madden-Julian oscillation: Implications for MJO prediction. Quart. J. Roy. Meteor. Soc., 133, 117-128.

Zeng, N., J. D. Neelin, and C. Chou, 2000: A quasi-equilibrium tropical circulation model-Implementation and simulation. J. Atmos. Sci., 57, 1767-1796.

Zheng, Y., D. E. Waliser, W. F. Stern, and C. Jones, 2004: The role of coupled sea surface temperatures in the simulation of the tropical intraseasonal oscillation. J. Climate, 17, 41094134. 